\title{
Four facets of classroom assessment: Obstacles, obligations, outcomes, and opportunities
}

\begin{abstract}
Authors: Lynn Kelting-Gibson, Nancy P. Gallavan, Eva St. Arnauld, Glenda L. Black, Andrea Cayson, Janine Davis, Kathy D. Evans, Patricia P. Johnson, Barbara Levandowski, Keenya Mosley, Debbie Rickey, Debra D Shulsky, Deborah Thomas, Amy M. Williamson, \& Jerald I Wolfgang
\end{abstract}

This is an Accepted Manuscript of an article published in Action in Teacher Education on December 2014, available online: http://www.tandfonline.com/10.1080/01626620.2014.977688.

Kelting-Gibson, L. M., N. Gallavan, Eva St. Arnauld, Glenda Black, Andrea Cayson, Janine Davis, Kathy D. Evans, Patricia P. Johnson, Barbara Levandowski, Keenya Mosley, Debbie Rickey, Debra D. Shulsky, Deborah Thomas, Amy M. Williamson, and Jerald I. Wolfgang. "Four facets of classroom assessment: Obstacles, obligations, outcomes, and opportunities." Action in Teacher Education 36, no. 5-6 (December 2014): 363-376.

doi: $10.1080 / 01626620.2014 .977688$ 
Four Facets of Classroom Assessments: Obstacles, Obligations, Outcomes, and Opportunities

ATE Commission on Classroom Assessment

Lynn Kelting-Gibson, Montana State University

Nancy P. Gallavan, University of Central Arkansas

Eva St. Arnauld, Grand Canyon University

Glenda L. Black, Nipissing University

Andrea Cayson, Florida State University

Janine Davis, University of Mary Washington

Kathy D. Evans, University of Tennessee at Martin

Patricia P. Johnson, Grambling State University

Barbara Levandowski, North Park University

Keenya Mosley, Savannah State University

Debbie Rickey, Grand Canyon University

Debra D Shulsky, University of Houston

Deborah Thomas, Georgia Southern University

Amy M. Williamson, Angelo State University

Jerald I Wolfgang, Niagara University

For submission to ATE Yearbook XXIII: Optimizing Teaching, Learning, and Schooling with

Classroom Assessment, Program Evaluation, and Educator Accountability

pages: 20

key words: classroom assessment, obstacles, obligations, outcomes, opportunities

Contact information:

Dr. Lynn Kelting-Gipson

Assistant Professor

Montana State University

121 Reid

Bozeman, MT 59717-2880

lynn.keltinggibson@montana.edu

406.994.7458

This chapter has not been submitted to any other publication. 


\begin{abstract}
Today's classroom teachers are expected to optimize the teaching, learning, and schooling so the educational experience is learner-centered, standards-based, achievement-oriented, and datadriven. These expectations require teachers to intensify their awareness, expand their understanding, reconfigure their practices, and modify their attitudes related to classroom assessments. As teachers shift their classroom assessment approaches to become the focus of their practices, and student assessments are more closely aligned with the curriculum and instruction, teachers encounter both challenges and rewards. This chapter describes four facets of classroom assessments--obstacles, obligations, outcomes, and opportunities--and the characteristics of each facet identified by teacher educators specializing in classroom assessments. The findings of this research make visible the value of examining the presence and power of each facet as both individual and integrated influences on teacher self-efficacy, emphasizing benefits for classroom teachers and teacher candidates in their transformation to develop classroom assessments that matter.
\end{abstract}




\section{Introduction}

Today's classroom teachers must be equipped and empowered with an abundantly rich and varied repertoire of classroom assessments that engage learners and produce data for teachers to analyze and apply to their practices. These data help them to fulfill three overarching professional goals: (1) increase learner achievement; (2) enhance their own self-efficacy; and (3) improve school programs and practices. Yet, in their quest to fulfill these goals, teachers are influenced by four facets of classroom assessments and the multiple characteristics associated with each facet that are visible and viable when planning, contextualizing, implementing, and reflecting on teaching, learning, and schooling. These four facets include the

(1) obstacles or barriers that hinder and/or prevent classroom teachers in their awareness, acquisition, application, and appreciation of classroom assessments,

(2) obligations or responsibilities required by national and state standards, school district and school administrator expectations, as well as student and family accountability and communications related to classroom assessments,

(3) outcomes or products resulting from classroom assessments providing a wide range of monitored and measured evidence useful to data collection, progress analysis, decision making, and teacher reflectivity, and

(4) opportunities or experiences that build upon the potential and maximize the possibilities to increase learner achievement, teacher self-efficacy, and school programs and practices.

Data provided by 13 teacher educators from the United States and Canada, members of the Association of Teacher Educators (ATE) Commission on Classroom Assessment, comprised a list of frequently cited characteristics for each individual facet, a ranked list of the most 
important characteristics for each facet, and the benefits of each facet. Like the sides of a diamond, each of the four facets provides a different plane or surface that refracts and intensifies light (Mason, 2011) illuminating various aspects intricate to classroom assessment. Similar to diamonds, each facet is unique in appeal (color), accuracy (clarity), appearance (cut), and accountability (carat) associated with classroom assessments. Together the four facets form the diamond, the hardest known natural material — the belief that many students and teachers associate with classroom assessment. In this chapter, the authors describe the four facets or forces that all educators (classroom teachers, school administrators, teacher candidates, and teacher educators) must recognize as accompanying the productive influences each facet shines on their practices.

\section{Accredited Teacher Preparation Programs and Classroom Assessment}

Accredited teacher preparation programs across the United States are guided by five standards established by the Council for the Accreditation of Educator Preparation (CAEP, 2013a). Candidate Knowledge, Skills, and Professional Dispositions, described in Standard 1 (CAEP, 2013b), state that

1.1 Candidates demonstrate an understanding of the ten InTASC standards at the appropriate progression level(s) in the following categories: the learner and learning; content; instructional practice; and professional responsibility.

This standard is coupled with four program provider responsibilities; one responsibility stipulates,

1.2 Providers ensure that completers use research and evidence to develop an understanding of the teaching profession and use both to measure their P-12 students' progress and their own professional practice. 
To comply with this standard and responsibility, teacher educators must review the ten Interstate Teacher Assessment and Support Consortium or InTASC standards authored by the Council of Chief State School Officers (CCSSO, 2011). Categorized as Instruction Practice, Standard \#6: Assessment specifies,

The teacher understands and uses multiple methods of assessment to engage learners in their own growth, to monitor learner progress, and to guide the teacher's and learner's decision making.

Ultimately, teacher candidates must be ready to develop curricular content, organize instructional strategies, and align assessment techniques for all learners and in all academic contexts based on the Common Core State Standards (CCSS) Initiative (2011) that "feature an increased focus on deeper learning on students' abilities to analyze, synthesize, compare, connect, critique, hypothesize, prove, and explain their ideas" (Darling-Hammond, Herman, Pellegrino, et al., 2013, p. i.). The CCSS cite that their standards are evidence-based and realistic for effective use in the classroom. Standards include both content and the application of knowledge through higher-order skills that clearly enable educators and parents to know what they need to do to help students learn (CCSS, 2011).

To this end, five valuable criteria inform and support high-quality assessments (DarlingHammond, Herman, Pellegrino, et al., 2013, p. i.):

1. Assessment of higher-order cognitive skills that allow students to transfer their learning to new situations and problems

2. High-Fidelity assessment of critical abilities as they will be used in the real world rather than through artificial proxies, i.e., performances that directly evaluate such skills as oral, 
written, and multimedia communication; collaboration; research; experimentation; and the use of new technologies

3. Assessments that are internationally benchmarked and evaluated against the assessments of the leading education countries in terms of the kinds of tasks they present as well as the levels of performances they expect

4. Use of items that are instructionally sensitive and educationally valuable including tests that are designed so that the underlying concepts can be taught and learned, rather than depending mostly on test-taking skills or reflecting students' out-of-school experiences. To support instruction, assessment also should offer effective models for teaching and learning providing insights into ways students think as well as the information

that they know

5. Assessments that are valid, reliable, and fair should accurately evaluate students' abilities, appropriately assess the knowledge and skills they intend to measure, be free from bias, and be designed to reduce unnecessary obstacles to performance that could undermine validity with positive consequences for the quality of instruction and the opportunities available for student learning

From planning to contextualizing, and implementing to reflecting on their classroom assessments, all educators and their learners benefit significantly and results are optimized when these five criteria frame their assessment processes.

\section{Conditions Impacting Teacher Preparation for Classroom Assessments}

However, four conditions exist that impact teacher preparation for classroom assessments. (1) Many educators (P-12 and higher education) have not received appropriate 
education for designing, conducting, and scoring classroom assessments, then analyzing the data and providing feedback gleaned from their classroom assessments. Black and Wiliam (1998) identify this absence of knowledge, skills, and dispositions as the "poverty of practice." (2) To compensate for limited experiences with classroom assessments, many educators tend to model their practices based on their own years as students and on their clinical field placements that Lortie (1975) calls the "apprenticeship of observation."

Thus, the impacts of the "poverty of practice" and the "apprenticeship of observation" (3) prompt many educators to construct their own classroom assessments that may or may not contribute positively or productively to the teaching, learning, and schooling. Continuing their unfounded approaches, many educators assess their students and model their assessments to their novice teachers through the "generational perpetuation of practices" (Gallavan, 2007). (4) Ultimately, without appropriate experiences or preparation, many educators tend to seek colleagues who can inform and reinforce their practices. The "establishment of relationships" (Gallavan \& Benson, in press) offers both exciting benefits and impairing detriments as educators construct their own approaches toward classroom assessments.

Most educators are unaware of these conditions and do not seek professional development to overcome and compensate the impact of these conditions on their practices. Too often, educators falsely presume that their preparation and practices are current and complete yet educators continue to be perplexed by their learners' achievements, their self-efficacy, and school's programs.

\section{Four Facets of Classroom Assessment}

Collectively the above four conditions exist in all four facets of classroom assessment as the (1) obstacles or barriers encountered for aligning relevant assessments with integrated 
curriculum and implementing instruction that engage students and teachers; (2) obligations or expectations established by educational researchers and governing agencies; (3) outcomes or products necessary for generating evidence and data; and (4) opportunities or experiences that contribute to student growth, teacher development, and institutional improvement. Each facet should be considered both independently as one perspective influencing classroom assessment and interdependently as one of four perspectives impacting the holistic nature of classroom assessment.

\section{Obstacles}

When discussing the obstacles related to classroom assessment that teachers and teacher candidates encounter, McMillan (2011) found that two sources of influence affect grading practices and assessment use. One source lies within the teacher and encompasses the values and beliefs about teaching and learning that provide a basis for explaining why and how specific assessment and grading practices are used. The second source is external to the teacher, pressures that need to be considered, such as high-stakes testing. McMillan expounds that "although internal beliefs and values that reflect a desire to enhance student learning are most influential, external pressures cause teachers to engage in certain practices that may not be in the best interests of student learning" (p. 21).

Another obstacle to fully implementing and understanding classroom assessment is teacher preparation. In his book Modern Classroom Assessment, Frey (2014) emphasizes the typical teacher education program has no course requirement in assessment, and many states do not mandate an assessment element. "The formal assessment training teachers do receive tends to focus on large-scale test administration and standardized test score interpretation rather than the variety of assessment formats available, assessment design strategies or item-writing 
guidelines" (p. 3). Several experts in the field of assessment feel that little has changed in the last few years related to the level of classroom teachers' assessment knowledge, even in this assessment-heavy nature of the classroom environment (Callahan, Griffo, \& Pearson, 2009; Stiggins, \& Chappuis, 2005).

Although the obstacle of teacher preparation for classroom assessments is a concern, there is another obstacle that classroom teachers and teacher candidates encounter - children's readiness for learning in the classroom. Green and Johnson (2010) explain, "Equal access to educational opportunity often doesn't seem to be happening the way it was intended. The underlying factors contributing to the achievement gap are varied and complex and start long before a child enters school" (p. 4). Lee (2008) found that an achievement gap already exists when students enter kindergarten (as cited in Green \& Johnson, 2010).

\section{Obligations}

Teacher and teacher candidates are expected to fulfill many obligations related to classroom assessments. "In the past decade large-scale accountability testing has had a significant impact on education at all levels" (McMillan, 2011, p. 2). McMillan adds, "Like it or not, it is abundantly clear that externally mandated high-stakes accountability tests have a profound impact on teaching and classroom assessment. What you do in the classroom will be influenced by both the content and the nature of these tests" (p. 19). "In the last decade unprecedented federal and state accountability testing policy initiatives have increased the pressure on schools to show positive test results. Increasing emphases on featuring "test prep," "teaching to the test," aligning classroom assessments with large-scale tests, and using classroom "test formats that are like the ones used in the state accountability tests" (p. 20). With regard to obligations related to assessments, Darling-Hammond et al., (2013) agree that teachers and 
teacher candidates "must create assessments that are valid, reliable, and fair: In order to be truly valid for a wide variety of learners, assessments hold measure well what they purport to measure, accurately evaluate students' abilities, and do so reliably across testing contexts and scorers. They should also be unbiased and accessible and used in ways that support positive outcomes for students and instructional quality" (p. 3).

Green and Johnson (2010) address the obligation of classroom assessment on our students. "As teachers, we must work with the children who come in our door, and we must do what is in our power to maximize learning for all our students and provide equal access to educational opportunity" (pp. 4-5). Teacher and teacher candidates also have obligations related to classroom assessments. What teachers do in the classroom will be influenced by both the nature and the content of standardized tests. And, some teachers have sadly learned that the stability of their professional careers may depend on their learners' achievement.

\section{Outcomes}

Another important facet of classroom assessment is to make the connection to outcomes. One such idea is from Chappuis, Commodore, and Stiggins, (2010). These authors claim district assessment systems serve to foster student success when they serve both formative and summative information needs across all levels of assessment use. McMillan (2011) reports, “...sound classroom assessment begins with a clear description of intended student competencies that result from student learning, and a clear statement of student outcomes" (p. 29). Like many characteristics of teaching, quality classroom assessment plays an essential role in affecting student learning and has a research-based set of best practices. But, this skill is sometimes treated as one of those important things that teachers are all magically able to do as soon as they are hired (Stiggins \& Chappuis, 2005). 
Outcomes include the educator's knowledge, skills, and dispositions; cognitive and metacognitive teaching and learning processes, collaborative and independent problem-solving, and immediate and high quality feedback (Davis \& Nietzel, 2011) within the school environment established by administrators' knowledge, skills, and dispositions_-particularly their expertise to guide and support assessments as intricate to teaching and learning. Sadler (1989) identifies two categories of assessment products as artifactual--written tests, assignments, projects, and studentproduced writing--and transient - participation in the processes associated with learning and assessment. Both artifactual and transient outcomes are dependent on the teacher's sense of understanding and control of the assessment process; the teacher's sense of efficacy and agency in aligning and refining the assessment with the curriculum and instruction; the teacher's senses of awareness of objectivity, fairness, subjectivity, and bias; and the application associated with assessment ranging from preassessments to formative assessments to summative assessments measured by teachers, peers, and self and the audiences of assessments encompassing the student, teacher, school, parent, and local, state, and national educational and civic communities.

\section{Opportunities}

Along with obstacles, obligations, and outcomes, a fourth facet to address is the wealth of opportunities related to classroom assessments. Frey (2014) claims that changes are needed and happening in some locations; there are new goals, purposes, perspectives, and roles for classroom assessments. He feels the most exciting part of today's classroom regarding assessment is that the diverse purposes for assessment, that teachers consider before choosing an assessment approach include purposes of assessment that could be different than the teachers of just a few years ago. Frey expresses, 
These approaches are different ways of thinking about assessment. They are choices that teachers make based on their philosophies, their goals, and their beliefs about the value and purpose of classroom assessment....teachers can build a classroom assessment culture driven by the thoughts and knowledge they have about assessment specifically and teaching in general. (p. 6)

Green and Johnson (2010) discuss this opportunity, “...we have come to see assessment as an amazingly flexible and comprehensive tool that has measurably improved our own teaching” (p. 3). They contend, “...that good assessment practices provide the opportunity for teachers, working in the realm when they have primary impact - their own classroom - to maximize learning for their students" (5).

With the current emphasis on the importance of formative assessment inclusion, McMillan (2011) suggests,

The goal of formative assessment is the improvement of student motivation and learning. To reach this goal, teachers must employ a circular, continuing process involving their evaluations of student work and behavior, feedback to students and instructional adjustments....This feedback, which either supports and extends proper understandings, or targets deficiencies, is followed by instructional adjustments that will build on understanding to broaden and expand their learning or correct misconceptions. (p. 99)

\section{Method}

\section{Research Questions}

Illuminating the four facets of classroom assessment manifested by the conditions impacting teacher preparation, members of the ATE Commission on Classroom Assessment organized a study to explore the characteristics of each facet. The overarching questions meant 
to achieve this goal are, What are the characteristics of each facet of classroom assessment? and What are the most important characteristics to share with classroom teachers and teacher candidates in their transformation to developing classroom assessments that matter?

This study utilized a mixed method that consisted of an open-ended response survey and a rating scale survey with 13 Commission on Classroom Assessment members responding to both. The open-ended questions on the first survey required commission members to answer questions regarding their experiences working with classroom teachers and teacher candidates concerning the four facets of classroom assessment. These responses were analyzed for themes and then placed into a second survey that listed the most common characteristics of each facet for ranking purposes. Commission members then ranked the characteristics for each facet on its importance.

\section{Participants}

The population of the study included the 13 member of the Commission on Classroom Assessment. Of the members, 11 are teacher educators, one is a classroom teacher, and one is a doctoral candidate from institutions and a school district around the United States and Canada. All of the members have K-12 classroom teaching experience and higher education teaching experience. The population participated on a volunteer basis.

\section{Data Collection Procedures}

Commission members were sent two surveys to complete on Survey Monkey. The first survey included participant information checks and anecdotal data response items regarding the four facets of classroom assessment. All 13 members completed the first survey. To determine the characteristics of each of the four facets the questions asked were 
Obstacles: What obstacles related to classroom assessments do classroom teachers and teacher candidates encounter (directly and/or indirectly)?

Obligations: What obligations related to classroom assessments are classroom teachers and teacher candidates required to fulfill (with their P-12 students, for the parents, and /or for the school administration)?

Outcomes: What outcomes related to classroom assessments are classroom teachers and teacher candidates expected to have their students produce?

Opportunities: What opportunities related to classroom assessment could classroom teachers and teacher candidates incorporate into their practices (planning, contextualizing, implementing, and reflecting on learning, teaching and schooling)?

The second survey included the most frequently cited characteristics from each of the four facets from the first survey. To determine which of the characteristics of each of the facets were most important, according to commission members, characteristics were ranked from 1 as being most important, to the higher number in each facet as being the least important.

\section{Data Analysis Strategies}

An analysis of the written descriptions of the commission members was conducted to discover the meaning of their experiences working with classroom teachers and teacher candidates. Characteristics were identified of what members considered as obstacles, obligations, outcomes, and opportunities related to classroom assessments for classroom teachers and teacher candidates. Common characteristics for the four facets of classroom assessment were identified. This analysis revealed the necessary characteristics to guide the researchers in determining the most important obstacles, obligations, outcomes, and opportunities that classroom teachers and teacher candidates need to know to shift their approaches so their 
classroom assessments become the focus on their practices and assessments are more closely aligned with the curriculum and instruction.

\section{Findings}

The findings of this study answered the two guiding questions: What are the characteristics of each facet of classroom assessment? and What are the most important characteristics to share with classroom teachers and teacher candidates in their transformation to developing classroom assessments that matter? The findings are presented as characteristics for each facet that emerged after commission members reflected on their experiences teaching in K12 and teacher preparation programs.

When asked about the obstacles that classroom teachers and teacher candidates encountered regarding classroom assessments the most commonly addressed characteristics were

- Having time to create and use a variety of assessments,

- Understanding what to assess and how to choose appropriate assessments,

- Aligning objectives/learning outcomes with assessments,

- Knowing what to do with assessment results,

- Creating valid and reliable classroom assessments,

- Viewing standardized tests as being synonymous with assessments, and

- Implementing differentiated classroom assessments.

The commission members were asked to rank obstacle items described previously as being most important to least important. The group felt that having time to create and use a variety of assessments as most important. Next important and in descending order are, understanding what to assess and how to choose appropriate assessments, aligning objectives/learning outcomes with 
assessments, and tie for fourth and fifth are knowing what to do with assessment results and creating valid and reliable classroom assessments were most important.

When asked about the obligations that classroom teachers and teacher candidates encountered regarding classroom assessments, the most commonly addressed characteristics were

- To show student growth/progress,

- To develop assessments aligned with standards,

- To make accommodations/differentiation decisions based on results,

- To use a variety of assessments,

- To use test results for teacher evaluation, and

- To give standardized/provincial assessments,

When the commission members ranked obligations related to classroom assessments as most important they ranked to show student growth/progress as most important. Next, in descending order were, to develop assessments aligned with standards, to make accommodations/differentiation decisions based on results, and to use a variety of assessments.

When asked about the outcomes that classroom teachers and teacher candidates encountered regarding classroom assessments the most commonly addressed characteristics were

- Meet individual student needs/differentiation,

- Meet proficiency levels/show growth,

- Show achievement aligned with state, provincial, and/or common core standards, and

- Show application of knowledge in a variety of ways, on assessment is not end result. 
When ranking outcomes the commission chose to meet individual needs/differentiation as their most important choice. To meet proficiency levels/show growths was next most important, and then show achievement aligned with state, provincial, and or common core standards. To show application of knowledge in a variety of ways, one assessment is not an end result, was the fourth most important.

When asked about the opportunities that classroom teachers and teacher candidates encountered regarding classroom assessments the most commonly addressed characteristics were

- To improve quality of instruction and learning,

- To use assessments to inform instruction,

- To increase student involvement in their own learning,

- To be reflective,

- To work collaboratively,

- To use action research,

- To provide professional development, and

- To use alternative/authentic forms of assessment.

When ranking opportunities the commission ranked to improve quality of instruction and learning as the most important. Next, to use assessments to inform instruction, and the final two most important were to increase student involvement in their own learning and to be reflective.

\section{Conclusions}

When investing in the purchase of a diamond, the buyer must understand and analyze the facets or surfaces of the diamond related to their appeal (color), accuracy (clarity), appearance (cut), and accountability (carat). Each of these four characteristics is equally important in the overall value of and appreciation for the diamond. 
Similarly, educators must understand and analyze four facets or surfaces of classroom assessment including the obstacles, obligations, outcomes, and opportunities. Obstacles, real or perceived, influence the appeal of the assessment; too often the obstacles distort the attraction of logical or innovative assessments that may simplify the teaching and learning for all audiences. Obligations, internal and external, impact the accuracy of the development and alignment of the assessment as well as the analysis of the data for current and future practices. Educators must acknowledge and be aware of the power that obligations place upon the variety of and engagement with classroom assessments.

Outcomes, by the students and the teacher, inspire participants to look beyond the superficial appearance of the classroom assessment for the authenticity and purposefulness of the assessment. The appearance of effective assessments cannot overshadow the legitimacy of the processes and products. Opportunities insure accountability for educators to apply their classroom assessments to new and different learning experiences empowering and equipping their students and themselves with tools and techniques to self assess, peer assess, and teacher assess, receiving feedback for personal growth and academic development. Effective classroom assessments will become a standard for educators beginning their careers, advancing their careers, and guiding other teachers in their careers, once they acknowledge the four conditions that impede effective classroom assessments and become more aware of the four facets of effective classroom assessments.

\section{References}

Black, P., \& Wiliam, D. (1998). Assessment and classroom learning. Educational Assessment: Principles, Policy, and Practice, 5(1), 7-74.

Common Core State Standards (CCSS) Initiative. (2011). Preparing America's students for 
college and career: Frequently asked questions. Retrieved from http://www.corestandards.org/frequently-asked-questions

Council for Accreditation of Educator Preparation (CAEP). (2013a). Accreditation standards. Retrieved from http://caepnet.org/2013/08/29/new-accreditation-standards-adopted/ Council for Accreditation of Educator Preparation (CAEP). (2013b.) Standards. Retrieved from http://caepnet.org/accreditation/standards/standard1/

Council of Chief State School Officers (CCSSO). (2011). The InTASC model core teaching standards. Retrieved from http://www.ccsso.org/Documents/2011/InTASC\%202011\% 20 Standards $\% 20 \mathrm{At} \% 20 \mathrm{~A} \% 20 \mathrm{Glance.pdf}$

Callahan, M., Griffo, V., \& Pearson, P. D. (2009). Teacher knowledge and teaching reading. In Frey, B. B. (2014), Modern classroom assessment. Los Angeles, CA: Sage.

Chappuis, S., Commodore, C., \& Stiggins, R. (2010). Assessment balance and quality: An action guide for school leaders. Upper Saddle River, NJ: Pearson Education.

Darling-Hammond, L., Herman, J., Pellegrino, J., Abedi, J., Aber, J. L., Baker, E., Bennett, R., Gordon, E., Haertel, E., Hakuta, K., Ho, A., Linn, R. L., Pearson, P. D., Popham, J., Resnick, L., Schoenfeld, A. H., Shavelson, R., Shepard, L. A., Shulman, L., \& Steele, C. M. (2013). Criteria for high-quality assessment. Stanford, CA: Stanford Center for Opportunity Policy in Education, Stanford University; Los Angeles, CA: Center for Research on Student Standards and Testing, University of California at Los Angeles; and Chicago, IL: Learning Sciences Research Institute, University of Illinois at Chicago. Retrieved from https://edpolicy.stanford.edu/publications/pubs/847

Davis, D. S., \& Neitzel, C. (2011). A self-regulated learning perspective on middle grades classroom assessment. The Journal of Educational Research, 104(3), 202-215. 
Frey, B. B. (2014). Modern classroom assessment. Los Angeles, CA: Sage.

Gallavan, N. P. (2007). Seven perceptions that influence novice teachers' efficacy and cultural competence. Praxis: Journal from the Center for Multicultural Education, 2(1), $6-22$.

Gallavan, N. P., \& Benson, T. (in press). Getting on the same PAGE: Illuminating teacher candidates' paths with customized student support services

Green, S. K., \& Johnson, R. L. (2010). Assessment is essential. Boston, MA: McGraw Hill Higher Education.

Lortie, D. (1975). Schoolteacher: A sociological study. Chicago, IL: University of Chicago Press.

Mason, J. (2011). Facet methodology: The case for an inventive research orientation. Methodological Innovations Online, 6(3), 75-92. Retrieved from http://www.pbs.plym.ac.uk/mi/pdf/8-02-12/MIO63Paper31.pdf

McMillan, J. H. (2011). Classroom assessment principles and practice for effective standardsbased instruction. Boston, MA: Pearson.

Sadler, D. R. (1989). Formative assessment and the design of instructional systems. Instructional Science, 18(2), 119-144.

Stiggins, R., \& Chappuis, J. (2005). Using student-involved classroom assessment to close achievement gaps. Theory into Practice, 44(1), 11-18. 